\title{
Estudio de la composición fisicoquímica de harina de semillas de zapallo como ingrediente alimentario
}

\section{Study of the physicochemical composition of pumpkin seeds flour as a food ingredient}

Escobar Gianni, Daniela Verónica ${ }^{(1)}$, Curutchet, Ana ${ }^{(2)}$, Zirbesegger, Heinz ${ }^{(3)}$, Márquez Romero, Rosa ${ }^{(1)}$

(1) Gerencia de Proyectos Alimentarios, Laboratorio Tecnológico del Uruguay (LATU), Uruguay - (2) Gerencia de Análisis y Ensayos, Laboratorio Tecnológico del Uruguay (LATU), Uruguay - ${ }^{(3)}$ Empresa Uru - Kürbis, Uruguay

Contacto: descobar@latu.org.uy

Recibido: 15/6/2012 - Aprobado: 13/12/2012

\begin{abstract}
$\underline{\text { Resumen }}$
La harina proveniente de la torta del prensado en la elaboración del aceite virgen de semilla de zapallo Cucurbita pepo var. styriaca, presenta características que la hacen interesante para su utilización en panificados y pastas, por su color verde característico, sabor intenso y valor nutricional. Para caracterizar este nuevo producto según su composición se realizaron elaboraciones de harina con semillas cultivadas en Uruguay y en Europa. Se determinaron humedad, materia grasa, proteínas, cenizas, fibras, sodio, vitamina B1, vitamina E, perfil de ácidos grasos, esteroles, aminoácidos y carbohidratos totales. Se estudió la estabilidad fisicoquímica y microbiológica durante 12 meses con la harina envasada en trilaminado de polietileno y poliéster aluminizado, almacenado en condiciones ambientales. La harina caracterizada es un producto proteínico vegetal (48,3\% proteína) y una importante fuente de fibras (11\% fibra). Tiene un $21,7 \%$ de lípidos, del cual el $38 \%$ son Ácidos grasos monoinsaturados AGM y el 53,4 \% Ácidos grasos poliinsaturados AGP, destacándose el ácido oleico y el linoleico que lo hacen deseable desde el punto de vista nutricional y culinario. Presenta $3,7 \mathrm{mg}$ de vitamina $E$ cada $100 \mathrm{~g}$ y $2967 \mathrm{mg} / \mathrm{kg}$ de esteroles. En la harina proveniente de la torta de prensado como subproducto del aceite virgen de la semilla de zapallo la acidez y la humedad se mantienen estables, mientras que la carga de hongos y levaduras disminuye a lo largo de 12 meses en el envase utilizado en este estudio, de trilaminado de polietileno, poliéster y aluminizado almacenado en condiciones ambientales.

Palabras clave: Harina, zapallo, panificados, pastas, celíacos.
\end{abstract}

\begin{abstract}
The flour from the presscake in the production of Cucurbita pepo var. styriaca seed virgin oil has features that make it interesting for use in baked goods and pasta production because of its characteristic green color, intense flavor and nutritional benefits. To determine the nutritional composition of this new product, elaborations of flour were made with seeds from Uruguay and Europe. They were analyzed for moisture, fat content, protein, ash, fiber, sodium, vitamin B1, vitamin E, fatty acid profile, sterols, amino acids and total carbohydrates. Physicochemical and microbiological stability have been studied for 12 months at ambient conditions with the flour packaged with a polyethylene, polyester and aluminum tri-laminate. The flour is characterized as a vegetable protein product $(48,3 \%)$ and as an important source of fiber $(11 \%)$. It has $21,7 \%$ of lipids of which $38 \%$ are MUFA and 53,4 \% are PUFA, highlighting the oleic and linoleic acid contents what makes it desirable from nutritional and culinary standpoints. It features $3,7 \mathrm{mg}$ of vitamin $\mathrm{E}$ per $100 \mathrm{~g}$ and $2967 \mathrm{mg} / \mathrm{kg}$ of sterols. In flour from the presscake in the production of pumpkin seed virgin oil acidity and moisture remains stable, while the fungi and yeasts number decrease during 12 months in ambient conditions used in this study, with trilaminate polyethylene aluminized polyester.

Keywords: Flour, pumpkin, baked goods, pasta, celiac.
\end{abstract}

\section{Introducción}

Cucurbita pepo var styriaca es una variedad de zapallo que se cultiva en Austria, Hungría, China, México y Nueva Zelanda. Posee una película exterior delicada en vez de una cáscara dura, lo que la hace atractiva tanto para su consumo como para el prensado directo para extraer el aceite.

En nuestro país es cultivada en distintas regiones (Montevideo, Canelones, Tacuarembó).

Hoy en día el cultivo de esta variedad del zapallo en Uruguay se destina a la producción de aceite virgen a partir de la semilla y a la venta de la semilla de zapallo tostada.

Como subproducto de la elaboración del aceite virgen de la semilla de zapallo Cucurbita pepo var. styriaca se obtiene la torta de prensado, con la harina como resultado de su molienda. En estudios realizados en aceite proveniente de cultivares de semilla de zapallo se encontró que dicho aceite es rico en vitamina $\mathrm{E}$ y esteroles vegetales, y que los ácidos grasos presentes en cantidad mayoritaria son el linoleico, oleico, palmítico y esteárico (Nyam et al., 2009; Stevenson et al., 2007). En torta de prensado de semilla de zapallo, Zdunczyk et al. (1999) reportaron valores de 59,8 \% de proteínas y al ácido oleico y linoleico como ácidos grasos encontrados en mayor proporción. Debido a su origen vegetal, al alto contenido de proteínas vegetales y 
la ausencia de contaminantes químicos, es atractiva para su uso en el área alimentaria.

En los países que actualmente producen este tipo de aceite el uso de la torta de prensado se aplica mayormente a la fabricación de raciones de animales (Vaštag et al., 2011).

La utilización de la harina proveniente de la torta de prensado como ingrediente en alimentos podría ser sin duda una innovación en la industria alimentaria local e internacional.

Aunque no existen antecedentes de la sustitución de harina de trigo por harina de torta de prensado de Cucurbita pepo var. styriaca, se encontraron estudios de sustitución de derivados de zapallo o de su semilla en productos panificados. El-Soukkary et al. (2001) sustituyeron la harina de trigo en un $21 \%$ por concentrado de proteína de semilla de zapallo en panes. Rakcejeva et al. (2011), por su parte, sustituyeron entre un 10 y un $25 \%$ de la harina de trigo por harina de zapallo en panes.

Rienet S.A. es una pequeña empresa agroindustrial de Uruguay que actualmente produce y comercializa el aceite virgen de la semilla de zapallo Cucurbita pepo var. styriaca y la semilla de zapallo tostada con marca de "Uru-kürbis". La empresa produce diversos productos y ha elaborado panes y pastas artesanalmente, sustituyendo hasta un $30 \%$ de la harina de trigo por la harina generada de la molienda de la torta de prensado del aceite, tal como se muestra en las Figuras 1 y 2. Si bien han sido degustados con éxito en varias oportunidades, no son comercializados actualmente.

Por todo esto podría ser interesante su utilización como ingrediente alimentario, con un uso potencial en pastas y productos panificados que le conferiría a éstos el carácter de productos enriquecidos en proteínas. Según el Codex Alimentarius, para que un producto pueda ser comercializado como "producto proteínico vegetal" tiene que ser definido como producto alimentario obtenido de materias primas vegetales mediante la reducción o eliminación de algunos de los principales constituyentes no proteínicos (agua, aceite, almidón, otros carbohidratos), de manera que se obtenga un concentrado de proteínas del $40 \%$ en base seca, o más.

Considerando el potencial que podría ofrecer esta harina como ingrediente, este trabajo pretende determinar la composición de la harina elaborada a partir de la molienda de la torta de prensado (subproducto de la producción del aceite virgen de semilla de zapallo), a los efectos de que pueda ser utilizada como ingrediente y determinar si puede cumplir los estándares para la futura categorización como "producto proteínico vegetal". Para todo esto se analizó la composición de la harina, sus fitoesteroles, el perfil de ácidos grasos, el contenido de sodio, vitaminas y aminoácidos en muestras provenientes de seis regiones de cultivo de semilla de zapallo y se estudió su estabilidad durante un año.

\section{Materiales y Métodos}

\section{Estudio de la composición fisicoquímica de la harina}

Para el estudio de la composición la empresa "Uru-kürbis" proporcionó el producto obtenido de la molienda de la torta de prensado del aceite, partiendo de seis muestras de distintas producciones de la harina. Se realizaron cuatro elaboraciones con semillas provenientes de cultivos de distintas regiones de Uruguay y las otras dos con semillas de Austria y Hungría.

Las semillas utilizadas fueron de Cucurbita pepo var. styriaca, la misma variedad tanto en Uruguay como en los dos países europeos, y por cada elaboración realizada se obtuvieron $50 \mathrm{~kg}$ de harina.

Se realizó prueba t de student a un $95 \%$ de confianza entre las muestras de la harina proveniente de las semillas producidas en Uruguay y de la harina con las semillas importadas de Austria y Hungría, para ver si existían diferencias significativas por la diferencia geográfica de las mismas.

A cada una de las muestras se les realizaron los siguientes ensayos según los métodos citados:

- Humedad: método gravimétrico, secado a $70{ }^{\circ} \mathrm{C}$ en estufa a vacío hasta peso constante, basado en "Pearson's Composition and Analysis of Foods".

- Materia grasa: extracción con éter de petróleo Método Soxtec, Foss-Tecator.

- Proteínas: método de Kjeldahl, basado en manual FOSS, método Application Note AN 3001

- Cenizas: método gravimétrico, por incineración en mufla, norma UNIT 548-82.

- Fibra alimentaria total: por método enzimático gravimétrico según AOAC 2007, método 985.29.

- Sodio: Espectrometría de Absorción Atómica por FAAS (llama aire-acetileno), según Método AOAC 973.54 adaptado, en muestra digerida según ISO 15587-2, Anexo C, adaptada.

- Vitamina B1: método de Sims y Shoemaker. AOAC Vol 76, $\mathrm{N}^{\circ} 5,1993$

- Vitamina E (Alfa tocoferol): según norma BS EN 12822, que consta en una saponificación y posterior extracción con solvente orgánico. La capa orgánica se inyectó directamente en HPLC luego de filtrar por 0,22 micras. La separación cromatográfica se hizo en fase normal (Phenomenex Silica) usando un detector de fluorescencia a $290-330 \mathrm{~nm}$.
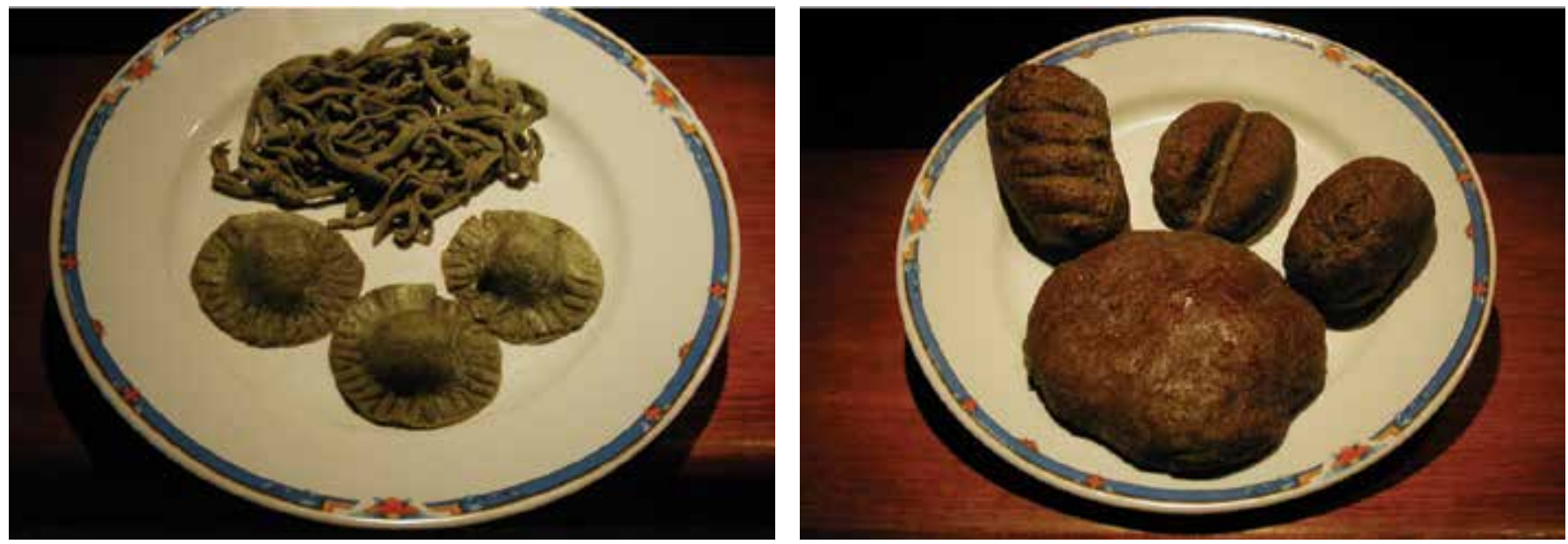

Figuras 1 y 2. Pastas y panes elaborados por la empresa "Uru-Kurbis" con harina de la torta de prensado de la semilla del zapallo (Cucurbita pepo var. styriaca). 
- Perfil de ácidos grasos: realizado por cromatografía gaseosa - espectrometría de masa siguiendo método oficial de AOCS Ce 2-66, AOCS Ce 1-62 y AOCS Ce 1-91. IRAM 5660

Composición y contenido de esteroles: basado en norma

- $\quad$ Aminoácidos: Análisis basado en AOAC 982.30.

- Carbohidratos Totales: por cálculo: 100 - (Humedad + Cenizas + Materia Grasa + Proteínas + Fibra Alimentaria Total).

- Valor energético: según el cálculo: 4 x (Carbohidratos Totales + Proteínas) +9 x (Materia Grasa).

\section{Estudio de estabilidad en el tiempo}

Se estudió la estabilidad, fisicoquímica y microbiológica durante 12 meses con la harina envasada en trilaminado de polietileno, poliéster y aluminio, almacenado en condiciones ambientales $\left(20^{\circ} \mathrm{C}\right)$. Debido a que la torta utilizada para obtener la harina es producto de un primer prensado y presenta cantidades importantes de aceite, se considera necesario medir la estabilidad del producto según la acidez, índice de peróxidos.

Los métodos y las frecuencias de los análisis fueron:

- Humedad: por método gravimétrico, secado a $70{ }^{\circ} \mathrm{C}$ en estufa a vacío hasta peso constante basado en "Pearson's Composition and Analysis of Foods". Este análisis se realizó a tiempo cero y una vez por mes.

- Índice de Peróxidos: Determinación sobre la materia grasa extraída. Método basado en la norma UNIT 642-82. Se determinó a tiempo cero y una vez por mes.

- Acidez: La materia grasa fue extraída con éter de petróleo utilizando soxtec y se disolvió en una solución de tolueno alcohol fenolftaleína, la cual es titulada con $\mathrm{NaOH} 0.02 \mathrm{~N}$ (basado en la norma AACC 0201). Este análisis se realizó a tiempo cero y una vez por mes.

- Recuento de hongos y levaduras: según APHA, "Compendium of Methods for the Microbiological Examination of
Foods". Se analizó a tiempo cero y luego cada cuatro meses.

\section{Resultados y Discusión}

\section{Composición fisicoquímica de la harina}

Se presentan en las Tablas 1 a 4 los resultados del estudio de composición fisicoquímica de la harina. Los valores detallados corresponden a los valores medios obtenidos con sus desviaciones estándar (DS).

La Tabla 1 especifica los valores de composición nutricional y de las vitaminas B1 y E en las muestras de harina de zapallo analizadas.

La harina producto de la molienda de la torta de prensado es una excelente fuente de proteínas y puede ser clasificada como "producto proteínico vegetal", dado que presenta en promedio un 48,3\% de proteína en base seca. Entre las harinas provenientes de la producción de aceites, hoy en día solo son utilizadas para consumo humano la de harina de soja desgrasada y la de harina de copra, cuyos porcentajes de proteínas promedio son del $43 \%$ para la soja y $22 \%$ para la copra (Centro de Comercio Internacional), valores superados por el nivel de proteínas en la harina de semillas de zapallo.

Presenta un aporte de fibra de 10,8 g / 100 g de harina. Según el Codex Alimentarius, es un alimento de alto contenido de fibra dietética si tiene más de $6 \mathrm{~g}$ por $100 \mathrm{~g}$ de alimento. El valor obtenido es similar al de harina de copra (12\%) y supera al de harina de soja (entre 6,5 y 7,0 g / 100 g), según el Centro de Comercio Internacional. La recomendación actual de consumo para la población en general es de 8 a $10 \mathrm{~g}$ de fibra / $1000 \mathrm{kcal}$ consumidas, de acuerdo al Manual para la Promoción de Prácticas Saludables de Alimentación en la Población Uruguaya.

La vitamina $\mathrm{E}$, de interés por su capacidad antioxidante, se encontró en niveles de 3,4 mg / $100 \mathrm{~g}$ en promedio. Esta vitamina es esencial para el organismo, ya que es un antioxidante que evita la destrucción normal de glóbulos rojos, evita trastornos oculares, anemias y ataques cardíacos. Su dosis diaria recomendada es de 15 $\mathrm{mg}$ para adultos y $6 \mathrm{mg}$ para niños (NAP).

\begin{tabular}{|c|c|c|c|c|c|c|}
\hline & \multicolumn{2}{|c|}{ Harina de Uruguay } & \multicolumn{2}{|c|}{$\begin{array}{c}\text { Harina europea } \\
\text { (Austria y Hungría) }\end{array}$} & \multicolumn{2}{|c|}{ TOTAL } \\
\hline & Valor medio & $\begin{array}{c}\text { Desviación } \\
\text { standard } \\
\text { DS }\end{array}$ & Valor medio & DS & Valor medio & $\begin{array}{c}\text { Desviación } \\
\text { standard } \\
\text { DS }\end{array}$ \\
\hline Humedad (g/100g) & 2,5 & 0,2 & 2,6 & 1,2 & 2,5 & 0,6 \\
\hline Cenizas (g/100g) & 8,1 & 0,3 & 8,5 & 0,6 & 8,2 & 0,4 \\
\hline Proteínas (g/100g) & 49,1 & 3,8 & 46,8 & 0,1 & 48,3 & 3,2 \\
\hline Materia grasa (g/100g) & 21,7 & 2,7 & 25,1 & 2,3 & 22,8 & 2,9 \\
\hline Fibra alimentaria total (g/100g) & 10,6 & 1,2 & 11,3 & 0,1 & 10,8 & 1,0 \\
\hline Carbohidratos totales (g/100g) & 8 & 3 & 6 & 1 & 7 & 2 \\
\hline Valor energético (Kcal/100g) & 425 & 18 & 436 & 15 & 429 & 17 \\
\hline Sodio (g/100g) & 1,1 & 0,4 & 0,73 & 0,01 & 1,0 & 0,3 \\
\hline Alfa tocoferol (mg/100g) & 3,7 & 1,3 & 2,8 & 0,5 & 3,4 & 1,2 \\
\hline Tiamina (mg/kg) & 0,9 & 0,2 & 1,3 & 0,2 & 1,0 & 0,2 \\
\hline
\end{tabular}

Tabla 1. Composición nutricional y valores de vitaminas E y B1 en la harina proveniente de las tortas de prensado de semillas de los distintos orígenes (Uruguay, y Austria y Hungría, según se indica en fila superior de la tabla).

No existe diferencia significativa al $95 \%$ de confianza entre las harinas de las semillas elaboradas con semillas de Uruguay y con semillas importadas de Europa. 


\begin{tabular}{|c|c|c|c|c|c|c|}
\hline & \multicolumn{2}{|c|}{ Harina de Uruguay } & \multicolumn{2}{|c|}{$\begin{array}{c}\text { Harina europea } \\
\text { (Austria y Hungría) }\end{array}$} & \multicolumn{2}{|c|}{ TOTAL } \\
\hline & Valor medio & DS & Valor medio & DS & Valor medio & DS \\
\hline $\operatorname{AGS}(g / 100 g)$ & 3,3 & 0,3 & 4,4 & 1,4 & 3,7 & 0,9 \\
\hline AGMI (g/100g) & 6,9 & 2,2 & 10,3 & 3,5 & 8,0 & 2,9 \\
\hline AGPI (g/100g) & 11,5 & 1,3 & 10,4 & 0,3 & 11,1 & 1,2 \\
\hline Grasa trans $(\mathrm{g} / \mathbf{1 0 0 g})$ & ND & ND & ND & ND & ND & ND \\
\hline AGI / AGS & 5,7 & 1,1 & 5,1 & 2,5 & 5,5 & 1,4 \\
\hline AGPI / AGS & 3,5 & 0,7 & 2,5 & 0,9 & 3,2 & 0,8 \\
\hline
\end{tabular}

Tabla 2. Tipos de grasas y relaciones en la harina proveniente de las tortas de prensado de semillas de los distintos orígenes (Uruguay, y Austria y Hungría, según se indica en fila superior de la tabla).

ND: no detectable.

AGS: Ácidos grasos saturados

AGMI: Ácidos grasos monoinsaturados

AGPI: Ácidos grasos poliinsaturados

AGI: Ácidos grasos insaturados $=$ AGMI + AGPI

No existe diferencia significativa al $95 \%$ de confianza entre las harinas de las semillas elaboradas con semillas de Uruguay y con semillas importadas de Europa.

La vitamina B1, cuya dosis diaria recomendada es de $0,6 \mathrm{mg}$ en niños y 1,2 $\mathrm{mg}$ en adultos (WHO/FAO 2002), presenta un nivel promedio en las muestras estudiadas de $1,0 \mathrm{mg} / \mathrm{Kg}$ de harina.

La Tabla 2 muestra las cantidades de los distintos tipos de grasa encontrados y sus relaciones más interesantes. La materia grasa total es de $22,8 \%$ en promedio. Este valor elevado era esperable porque la harina es el subproducto principal de la producción de aceite virgen de un solo prensado. Comparado con los niveles en las harinas de soja y de copra es mucho mayor ( 0,5 y $6,0 \%$ para soja y copra, respectivamente, de acuerdo al Centro de Comercio Internacional).

La harina presentó una mayor proporción de AGI que de AGS (relación 5,5 en promedio total). La mayor ingesta de AGI favorece la disminución de colesterol, precursor de enfermedades cardiovasculares. También se encontró una relación favorable de AGPI/AGS (3,2 en promedio total), que se recomienda sea mayor a 1.

\begin{tabular}{|c|c|c|c|c|c|c|c|}
\hline & & \multicolumn{2}{|c|}{ Harina de Uruguay } & \multicolumn{2}{|c|}{$\begin{array}{c}\text { Harina europea } \\
\text { (Austria y Hungría) }\end{array}$} & \multicolumn{2}{|c|}{ TOTAL } \\
\hline & & Valor medio & DS & Valor medio & DS & Valor medio & DS \\
\hline C 16:0 & Palmítico & 10,4 & 1,5 & 11,7 & 4,7 & 10,8 & 2,5 \\
\hline C 18:0 & Esteárico & 4,4 & 0,7 & 5,5 & 2,2 & 4,7 & 1,3 \\
\hline C 18:1 cis & Oleico & 31,1 & 7,3 & 40,1 & 10 & 34,1 & 8,6 \\
\hline C 18:2 cis & Linoleico & 53,1 & 6,5 & 41,1 & 2,1 & 49,1 & 8,0 \\
\hline
\end{tabular}

Tabla 3. Principales ácidos grasos (\% masa) encontrados en la harina proveniente de las tortas de prensado de semillas de los distintos orígenes (Uruguay, y Austria y Hungría, según se indica en fila superior de la tabla).

No existe diferencia significativa al $95 \%$ de confianza entre las harinas de las semillas elaboradas con semillas de Uruguay y con semillas importadas de Europa. En el ácido linoleico se encontró diferencia significativa al 10 \% con p-valor de 0.727 .

Como se ve en la Tabla 3, el ácido graso principal encontrado en la composición lipídica de la harina fue el linoleico (C 18:2 cis), con el $49,1 \%$, seguido por el oleico, con el $34,1 \%$, y luego el palmítico, con el 10,8 \%.

Se halló una diferencia (al $90 \%$ de confianza) en los perfiles estudiados en las semillas provenientes de Uruguay que presentaron mayor porcentaje de ácido linoleico (53,1\% en promedio) que las provenientes de Europa ( $41,1 \%$ en promedio). En estudios realizados por Applequist et al. (2006) del perfil de ácidos grasos en semillas de Cucurbita pepo de distintas especies, el ácido linoleico fue el que se presentó en mayor proporción, con valores que variaron entre 40,4 y 57,2 \%. El mismo autor reporta en segundo lugar al oleico, con valores entre 21,0 y $37,2 \%$, y en tercer lugar al palmítico, con valores entre 11,7 y $15,6 \%$.

Desde el punto de vista nutricional, los aportes de ácido linoleico, ácido graso esencial y de ácido oleico son beneficiosos dados los aspectos favorables que representan para la salud humana. Además, el ácido oleico beneficia la disminución de la oxidación del colesterol-LDL y mejora la palatabilidad del producto final.

El ácido palmítico desde el punto de vista tecnológico es favorable para la plasticidad y estabilidad en productos finales. 
Respecto al contenido de esteroles, se encontraron en niveles promedio de $2967 \mathrm{mg} / \mathrm{kg}$ de harina de las muestras estudiadas. El esterol encontrado en mayor proporción en todas las muestras $(57,7$ $\mathrm{g} / \mathrm{kg}$ de harina promedio) no pudo ser identificado, y presenta un tiempo de retención que coincide con el del $\beta$-sitoesterol. Le siguen en proporciones variables el D7,25-estigmastadienol y el D7-avenasterol, completando entre estos tres esteroles el $91 \%$ de los esteroles totales. La presencia de esteroles en la dieta es de interés para la prevención de enfermedades cardiovasculares.

\begin{tabular}{|l|c|c|c|}
\hline $\begin{array}{l}\text { Aminoácidos } \\
\text { (mg/g proteínas) }\end{array}$ & $\begin{array}{c}\text { Requerimiento } \\
\text { WHO/FAO/ONU } \\
\text { para niños de } \\
\mathbf{3} \text { a 10 años }\end{array}$ & $\begin{array}{c}\text { Requerimiento/FAO/ONU } \\
\text { pHOra adultos } \\
\text { parina de semilla } \\
\text { de zapallo } \\
\text { (valores } \\
\text { promedio } \\
\text { obtenidos) }\end{array}$ \\
\hline Histidina & 16 & 15 & 27,8 \\
\hline Isoleucina & 31 & 20 & 48,5 \\
\hline Lisina & 48 & 30 & 33,9 \\
\hline Leucina & 61 & 39 & 66,6 \\
\hline Metionina + Cisteína & 24 & 15 & 23 \\
\hline Fenilalanina + Tirosina & 41 & 25 & 91,9 \\
\hline Treonina & 25 & 15 & 31,6 \\
\hline Triptofano & 6,6 & 4 & 7,7 \\
\hline Valina & 40 & 26 & 48,3 \\
\hline
\end{tabular}

Tabla 4. Comparación de necesidades de aminoácidos esenciales en diferentes grupos etáreos con su cantidad en la harina de zapallo.

La harina proveniente de la semilla de zapallo contiene todos los aminoácidos esenciales, tal como lo muestra la Tabla 4, y estos son el $45 \%$ de los aminoácidos totales encontrados. De acuerdo a los requerimientos diarios que recomiendan WHO/FAO/ONU (2007), presentan interés para la población infantil todos los aminoácidos esenciales excepto la lisina, metionina y cisteína, que se encuentran por debajo de las necesidades establecidas para dicha población. Para la población de adultos son de interés los niveles de todos los aminoácidos esenciales presentes en la harina de zapallo.

\section{Estabilidad en el tiempo}

En la Tabla 5 se expresan los resultados de los parámetros analizados en los 12 meses del estudio.

\begin{tabular}{|c|c|c|c|c|}
\hline $\begin{array}{c}\text { Tiempo } \\
\text { (meses) }\end{array}$ & $\begin{array}{c}\text { Humedad } \\
\text { (g/100g) }\end{array}$ & $\begin{array}{c}\text { Acidez } \\
\text { (g oleico/100 g } \\
\text { materia grasa) }\end{array}$ & $\begin{array}{c}\text { Indice de } \\
\text { peróxidos } \\
\text { (meq. peróx/kg } \\
\text { materia grasa) }\end{array}$ & $\begin{array}{c}\text { Recuento } \\
\text { de hongos } \\
\text { y levaduras } \\
\text { (UFC/g) }\end{array}$ \\
\hline 0 & 3,7 & 0,70 & $6($ Rango $=1)$ & 1700 \\
\hline 1 & 3,3 & 0,80 & - & - \\
\hline 2 & 3,2 & 0,60 & 9 (Rango $=2)$ & - \\
\hline 3 & 3,6 & 0,63 & 12 (Rango $=3)$ & - \\
\hline 4 & 3,8 & 0,48 & 7 (Rango $=3)$ & 250 \\
\hline 5 & 2,9 & 0,53 & 9 (Rango $=1)$ & - \\
\hline 6 & 2,5 & 0,83 & 9 (Rango $=1)$ & - \\
\hline 7 & 2,4 & 0,61 & 9 & - \\
\hline 8 & 2,6 & 0,52 & 8 (Rango $=2)$ & 160 \\
\hline 9 & 2,7 & 0,55 & 10 & - \\
\hline 10 & 2,5 & 0,58 & 8 & - \\
\hline 11 & 2,6 & 0,54 & 9 & - \\
\hline 12 & 3,1 & 0,80 & $12($ Rango $=4)$ & 55 \\
\hline
\end{tabular}

Tabla 5. Resultados de los análisis realizados a lo largo del estudio de estabilidad.
De los estudios fisicoquímicos se observa que la humedad de la harina que inicialmente es de 3,7\% presenta valores menores a 3,1\% entre los 5 y 12 meses, mientras que la acidez se mantiene estable durante el tiempo de estudio. Desde el punto de vista microbiológico se produce una disminución con el tiempo del recuento de hongos y levaduras.

\section{Conclusiones}

La harina presenta un porcentaje de proteína del 48,3 g /100 g en base seca, lo que permite que pueda ser comercializada como "producto proteínico vegetal" según Codex Alimentarius, que establece que se deberá presentar por lo menos un $40 \%$ de proteína en base seca. Es fuente de fibra, con $10,8 \mathrm{~g} / 100 \mathrm{~g}$, así como de vitamina $\mathrm{E}$, con 3,4 mg $/ 100 \mathrm{~g}$ de harina, además de contener aminoácidos esenciales.

Adicionalmente, tiene ventajas en su composición nutricional, ya que presenta una relación de grasas insaturadas/saturadas de 5,5 y su ácido graso principal es el ácido linoleico cis $(49,1 \%)$, el cual se considera esencial para el crecimiento.

La harina proveniente de la torta de prensado como subproducto del aceite virgen de la semilla de zapallo mantiene estables la acidez y humedad, mientras que la carga de hongos y levaduras disminuye a lo largo de 12 meses, en el envase utilizado en este estudio, de trilaminado de polietileno, poliéster y aluminizado almacenado en condiciones ambientales.

Con este trabajo se tiene una base de información para una próxima caracterización de producto que pueda permitir su introducción en forma comercial. Por otra parte, se entienden convenientes los estudios a futuro de la incorporación de la harina como ingrediente en productos panificados y de aceptación de los productos por parte de los consumidores.

\section{Reconocimientos}

LATU: Departamento de Desarrollo de Métodos Analíticos, Departamento de Productos Lácteos, Cárnicos, Hortifrutícolas y de la Colmena, Departamento de Cereales, Oleaginosos y productos derivados, Centro de Información Técnica.

\section{Referencias}

- AACC INTERNATIONAL. Approved methods of analysis. 10a ed. St. Paul: AACC International, 2000. Method 02-01 A.

- AMERICAN OIL CHEMIST'S SOCIETY. Official methods and recommended practices of the AOCS. 6a ed. Urbana: AOCS, 2009. Official Method Ce 1-62.

- AMERICAN OIL CHEMIST'S SOCIETY. Official methods and recommended practices of the AOCS. 4a ed., reapproved 1993. Urbana: AOCS, 1995. Official Method Ce 1-91.

- AMERICAN OIL CHEMIST'S SOCIETY. Official methods and recommended practices of the AOCS. 6a ed. Urbana: AOCS, 2009. Official Method Ce 2-66.

- AMERICAN PUBLIC HEALTH ASSOCIATION. Compendium of methods for the microbiological examination of foods. $4 \mathrm{a}$ ed. Whashington: APHA, 2001. Capítulo 20.

- AOAC INTERNATIONAL. Official methods of analysis of AOAC International. 18a ed., 2da. rev. Gaithersburg: AOAC, 2007. Official Method 973.54.

- AOAC INTERNATIONAL. Official methods of analysis of AOAC International. 18a ed., 2da. rev. Gaithersburg: AOAC, 2007. Official Method 982.30.

- AOAC INTERNATIONAL. Official Methods of Analysis of AOAC International. 18a ed., 2da. rev. Gaithersburg: AOAC, 2007. Official Method 985.26.

- APPLEQUIST, W.; AVULA, B.; SCHANEBER, B.T.; WANG, Y.; KHAN, I.A. Comparative fatty acid content of seeds of four Cucurbita species grown in a common (shared) garden. En: Journal of Food Composition and Analysis. 2006, 19:606-611. 
- BRITISH STANDARD INSTITUTION (Inglaterra). BS EN 12822: Foodstuffs. Determination of vitamin $E$ by high performance liquid chromatography. Measurement of $\alpha$-, $\beta$-, $\gamma$ - and $\delta$ - tocopherols. Londres: BSI, 2000.

- CENTRO DE COMERCIO INTERNACIONAL. Tortas de aceite y harinas oleaginosas : los desafios del mercado para los países en desarrollo. Ginebra: CCI, 2000.

- EL-SOUKKARY, F.A. Evaluation of pumpkin seed products for bread fortification. En: Plant Foods for Human Nutrition 2001, 56(4):365384

- FAO; OMS. Comisión del Codex Alimentarius: Directrices generales del Codex para la utilización de productos proteínicos vegetales (PPV) en los alimentos. CAC/GL 4-1989. Roma: FAO, 1996.

- FAO; OMS. Human vitamin and mineral requirements. Report of a joint FAO/WHO expert consultation. Roma: FAO, 2002.

- FAO; WHO; UNU. Protein and amino acid requirements in human nutrition: report of a joint FAO/WHO/UNU expert consultation. Ginebra: OMS, 2002 (WHO technical report series; 935).

- INSTITUTO ARGENTINO DE NORMALIZACIÓN Y

CERTIFICACIÓN (Argentina). IRAM 5660: Aceites comestibles e industriales. Método de análisis de la fracción de esteroles extraída de la materia insaponificable por cromatografia en fase gaseosa. Buenos Aires: IRAM, 1981.

- INSTITUTO URUGUAYO DE NORMAS TÉCNICAS (Uruguay). UNIT 548: Productos para alimentación animal. Determinación del contenido de cenizas. Método de referencia. Montevideo: UNIT, 1982.

- INTERNATIONAL ORGANIZATION FOR STANDARDIZATION (Suiza). ISO 15587-2: Water quality. Digestion for the determination of selected elements in water. Part 2: Nitric acid digestion. Ginebra: ISO, 2002.

- KIRK, R.S.; SAWYER, R. Pearson's composition and analysis of foods. 9a ed. Nueva York: Longman, 1991.

- NYAM, K.L.; TAN, C.P.; LAI, O.M.; LONG, K.; CHE MAN, Y.B. Physicochemical properties and bioactive compounds of selected seed oils. En: Food Science and Technology. 2009, 42(8):1396-1403.

- RAKCEJEVA, T.; GALOBURDA, R.; CUDE, L.; STRAUTNIECE, E. Use of dried pumpkins in eheat bread production. En: Procedia Food Science 2011, 1:441-447.

- SIMS, A.; SHOEMAKER, D. Simultaneous liquid chromatographic determination of thiamine and riboflavin in selected foods. En: Journal of AOAC International. 1993, 76(5):1156-1160.

- STEVENSON, D.; ELLER, F.; WANG, L.; JANE, J.; WANG, T.; INGLETT, G. Oil and tocopherol content and composition of pumpkin seed oil in 12 cultivars. En: J. Agric. Food Chem. 2007, 55:40054013.

- URUGUAY. MINISTERIO DE SALUD PUBLICA. Manual para la promoción de prácticas saludables de alimentación en la población uruguaya. Montevideo: MSP. Dirección general de la salud. Programa Nacional de Nutrición, 2005.

- VAŠTAG, Z.; POPOVIC, L.; POPOVIC, S.; KRIMER, V.; PERICIN, D. Production of enzymatic hydrolysates with antioxidant and angiotensin-I converting enzyme inhibitory activity from pumpkin oil cake protein isolate. En: Food Chemistry. 2011, 124:1316-1321.

- ZDUNCZYK, D.; MINAKOWSKI, S.; FREJNAGEL, S. Comparative study of the chemical composition and nutritional value of pumpkin seed cake, soybean and casein. En: Food / Nahrung 1999, 43(6):392-395. 1974, 22:796-800. 